\title{
THE EARTH AS SOUNDSCAPE: A VERY SKETCHY PORTRAIT OF A VERY NOISY PLANET
}

\author{
STANISŁAW PUPPEL
}

\begin{abstract}
The earth forms a gigantic sound theatre. The sound arena, as we may also call it, has been formed in a number of phases. They include the following: the phase of the formation of the natural sound arena (geophony), the formation of the bio sound arena (biophony/zoophony), the phase of the formation of the human sound arena (anthropophony), the phase of the formation of machine-produced sound arena (technophony). All of them are merged into the Earth's soundscape. In ecological terms, technophony should be kept at a minimum if the Earth's overall wellbeing is to be considered seriously.
\end{abstract}

Key words: geophony, biophony/zoophony, anthropophony, technophony, phonic wellbeing

\section{Introduction}

The Earth is noisy; it is home to sounds. It is a kingdom of sounds which fill her both in the tangible and intangible dimensions. It is especially the tangible dimension which follows from the Earth's being a solid carrier of life surrounded by atmosphere and which is the subject matter of the present sketchy outline. The structure of atmosphere which is a layer of gases surrounding the Earth comprises: troposphere, stratosphere, mesosphere, and thermosphere. The troposphere layer, which extends from the Earth's surface up to 7 kilometers over the pole and 16 kilometers over the equator, is the most important layer, since about $75 \%$ mass of all environmental gases and about $99 \%$ water vapour and dust particles are located in this layer. The Earth's atmospheric composition includes: about $78 \%$ of nitrogen, about $21 \%$ of oxygen, about $0.9 \%$ of argon, $0.04 \%$ of carbon dioxide and other gases (such as neon, helium methane, krypton, hydrogen, etc.) in minimum (trace) 
amounts. These evolutionarily produced proportions are necessary for the Earth's soundscape to appear and function with all the might allowed for by the presence of the air in its above mentioned composition.

\section{The Earth as a Grand Sound Theatre (GST)}

On the basis of considerable knowledge accumulated over decades of research on the evolution and history of our planet, we may safely assume that the Earth forms a gigantic sound theatre, a Grand Sound Theatre (GST), with a major protagonist whose collective name is the 'soundscape' and which 'performs' and 'expresses' appropriately. Moreover, the Earth's soundscape has been established as a result of billions of years of gradual modifications and establishment of the atmosphere with the necessary participation of living organisms. It has included the following phases:

1. The phase of carrier installation in which the Earth was formed by: (a) accretion of matter from the solar nebula, (b) going through a number of collisions with other cosmic bodies that have kept the newly formed planet in a molten condition and under extreme volcanism, (c) being involved in a giant impact collision with a planet-sized body named Theia which has led to the formation of the Moon, (d) cooling of the Earth which caused the formation of a solid Earth crust, and (e) finally, allowing the appearance of atmosphere and water on the surface of the Earth. In this way, the conditions for sound propagation on a habitable planet have finally been established.

2. The phase of the formation of the Natural Sound Arena (NSA) in which the Earth became a noisy planet, or full of natural sounds and at the same time a place of busy and constant sound production. The sounds produced on the Earth's surface are the result of the co-occurrence of the planet's structure and of the air with its propagating properties which fills the troposphere and in which all the natural objects are immersed. The NSA functions like a Great Natural Orchestra performing its natural (noisy and chaotic) music in the GST and includes, among others, the following and really powerful instances of our planet's natural and noisy orchestral performances:

- roaring oceans and seas,

- erupting volcanos,

- winds and hurricanes,

- waterfalls and floods,

- falling rocks and rolling stones,

- heavy rainfalls,

- thunderstorms,

- avalanches,

- fires, 
- cracking ice,

- cracking and falling trees and branches.

In the NSA phase, all the sounds which are performed by this Great Natural Orchestra and which thus constitute geophony, do not compete with each other but employ the air and its acoustic potential in the ear-free fashion. This means that, for example, avalanches do not 'hear' the roaring of the oceans. Nor all the other performances mentioned above are carried out in any pre-planned and desired fashion. In other words, the air is not transduced in any way and geophony manifestations remain 'wild' in the sense of being generally uncontrolled, chaotic, unplanned and uncompetitive with respect to each other.

3. The phase of the formation of the Bio Sound Arena (BSA) in which a number of species which have occurred on the surface of the Earth (habitable planet) have developed rich communication systems based on the sense of hearing and mechanisms of sound production (see e.g. Puppel, 1988; Puppel, to be published). These systems are understood as forming biophony (zoophony, to be more precise) which is based on air transduction and the formation and possession of appropriate air transducing mechanisms (e.g. insect singing, the ears in birds and mammals which followed the more primitive reptilian hearing via skull bones). The following instances of biophony may be enumerated:

- insect singing (cicadas, grasshoppers, locusts, crickets),

- snake rattling

- bird singing

- animal (both aerial and aquatic) roars and calls.

In the BSA phase, all the sounds signal the presence of a species which occupies a selected region of biophony and where all the sounds are performed by what may be called the Bio Sound Orchestra, this time on a combined competitive and integrative basis. Competitions appear to be of the inter-species and intra-species character. The inter-species type of biophony manifestations has the aim of both providing a phonic challenge to other species and demonstrating alertness and readiness to go into combat (most notably territorial defenses). In turn, the intra-species type of integrative biophony manifestations has the aim of both focusing on the attractiveness of the males (aiming at achieving reproductive success) and on species integration via a myriad of phonic identities which have been developed in the animal world.

The transduction mechanism of every animal, which converts the mechanistic properties of the air, introduces to the Earth's soundspace the phenomenon and imperative of rule-based phonic behavior. The latter presupposes the acquisition and establishment of 'knowledge' understood as: the knowledge of the external environment, recognition of the species vis-à-vis other species, the knowledge of the animal's own transduction and sound production mechanisms, etc. In other words, the transduction mechanism operates within the entire air potential but utilizes only 
a small fraction of that potential reflected in the particular rules of biophonic behaviour. These rules are recognizable to the members of the species and include such activities as: observation of the external conditions, goal recognition, identification and evaluation of the external conditions, planning a particular phonic task, and execution of the task by means of appropriate (specialized) anatomical organ(s). It is obvious that rule-based phonic behavior constitutes a great leap from geophony to biophony.

4. The phase of the formation of the Human Sound Arena (HSA) in which all the sounds are displayed (i.e. they compete with each other for distinctiveness and intensity) in larger phonic structures, such as syllabic sequences, spoken words, phrases, texts. They constitute, like the sounds generated in biophony, only a small fraction of the entire acoustic potential of the Earth and form the anthrophony directed by the imperative of rule application which has been established over thousands of years of evolutionary adaptations. As in the animal world, the transduction mechanism is based on the presence of human ears, an extremely complex anatomical mechanism which operates within the entire air potential. The rules are easily recognizable to all the members of the species Homo sapiens and allow for the generation of sounds by the Anthropo Sound Orchestra through the maintenance of such activities as: observation of the external conditions, goal recognition, identification and evaluation of the external conditions for a particular phonic task, planning a particular phonic task, and execution of the task by means of a highly specialized audio-vocal mechanism, thus indicating that humans share perceptual mechanisms with the animal world.

In addition, all these activities are carried out in the framework of the intangible dimension of 'language' which, while being organized and integrated by 'system', that is, around the phenomena of separation (distinctiveness, opposition) and combinatorial power of functional units of various sizes, including the phonic units as the smallest functional units, constitutes the highest level of the highly specialized and most sophisticated human phonic behavior. It should also be added, that the phonic behavior of man (anthrophony) is based on smooth, regular (patterned), aesthetically pleasant (i.e. pleasing all the senses) sounds of definite pitch in contrast to the rough, irregular, unpleasant sounds of no definite pitch which characterize the sounds of the domain of geophony presented above. Thus, human phonic performances, which are the part and parcel of the oral communication order and oral culture, are at the same time the most sophisticated and most pleasant and most aesthetic phonic behaviors in the entire Grand Sound Theatre.

5. The phase of the formation of the Machine-produced Sound Arena (MSA) in which, as in the phase of Natural Sound Arena, the Earth is again filled with noisy sounds which are characterized as being chaotic and uncompetitive but at the same time as being the result of all kinds of machines manufactured by man. These sounds constitute what may be called technophony which comprises all anthropogenic noises 
produced by various machines (mechanical appliances) in the course of human history. Throughout its entire span, countless generations of human beings were busily involved in the production and maintenance of technophony. Today, its dimensions are truly gigantic and cover all corner of the planet. In fact, we can say that we live in some kind of technophonic oppression (e.g. the oppression of growing city noise, of industrial noise and growing aviation noise) which participates in immersing us all in man-made noise and essentially in reducing our phonic wellbeing.

\section{The fusion of all the orchestras into the Earth's Soundscape (ES)}

The Orchestras mentioned above, constituents of the Grand Sound Theatre (GST), where they are involved in performing various non-symphonic performances (i.e. based on phonic dissonance), on the one hand, combined with man's symphonic performances (i.e. based on phonic assonance), on the other, may be regarded as forming a phonic/sonic whole, the Earth's Soundscape (ES).

On the purely ecological level of reference, one should state that in terms of ES conservation, only the biophony and anthropophony dimensions are worth conserving by man due to their great biological diversity potential and non-jeopardizing presence. It should also be emphasized at this point that this potential, while being non-destructive to man's health, is involved in functioning in unison with all of biophony (zoophony) as a manifestation of the overall biological unity. On the other hand, the dimension of geophony is inevitable and naturally self-conserving, while technophony, being an unnatural (man-made) and acoustically polluting intrusion on the human and animal hearing systems, should be kept at a minimum if the human kind should take a serious interest in the development of its and the Earth's overall wellbeing, including the phonic wellbeing as one of its essential ingredients.

\section{Selected bibliography concerning soundscape}

Albert, J.T. and A.S. Kozlov. 2016. "Comparative aspects of hearing in vertebrates and insects with antennal ears". Current Biology 26. R1050-R1061.

$\mathrm{Au}$, W.L. 2000. Hearing by whales and dolphins. Berlin: Springer-Verlag.

Bart, F.G., P. Giampieri-Deutsch and H.D. Klein. (eds.). 2012. Sensory perception: mind and matter. Vienna: Springer-Verlag.

Beranek, L.L. (ed.). 1991. Noise reduction. Newport Beach, CA: Peninsula Publishing.

Bowler, P.J. 1996. Life's splendid drama: evolutionary biology and the reconstruction of life's ancestry, 1860-1940. Chicago: The University of Chicago Press.

Christensen-Dalsgaard, J. and G.A. Manley. 2005. "Directionality of the lizard ear". Journal of Experimental Biology 208. 1209-1217.

Dooling, R.J., R.R. Fay and A.N. Popper. (eds.). 2000. Comparative hearing: birds and reptiles. Berlin: Springer-Verlag.

Droumeva, M. and R. Jordan. (eds.). 2019. Sound, media, ecology. Cham, Switzerland: Palgrave Macmillan.

Forty, R. 1999. Life: a natural history of the first four billion years of life on Earth. London: Vintage Books. 
Kasting, J.F. and D. Catling. 2003. "Evolution of a habitable planet". Annual Review of Astronomy and Astrophysics 41.1. 429-463.

Ludman, H. (ed.). 1988. Mawson's diseases of the ear. $5^{\text {th }}$ ed. London: Edward Arnold.

Lunine, J.I. 1999. Earth: evolution of a habitable world. Cambridge: Cambridge University Press.

Manley, G.A. 1990. Peripheral hearing mechanisms in reptiles and birds. Heidelberg/New York: Springer-Verlag.

Manley, G.A., A.N. Lukashkin, P. Simões, G.W.S. Burwood and I.J. Russell. 2018. "The mammalian ear: physics and the principles of evolution". Acoustics Today 14.1. 8-16.

Pickles, J.O. 2008. An introduction to the physiology of hearing. $3^{\text {rd }}$ ed. Bingley, UK: Emerald Group.

Plack, C.J. 2013. The sense of hearing. London: Routledge.

Pulkki, V. and M. Karjalainen. 2015. Communication acoustics: an introduction to speech, audio and psychoacoustics. New York: Wiley and Sons.

Puppel, S. 1988. Aspects of the psychomechanics of speech production. Poznań: Wydawnictwo Naukowe UAM.

Puppel, S. 2009. "Antropofenetyka: uwagi w sprawie ekologii narządów mowy i utrzymywania estetycznej publicznej przestrzeni dźwiękowej” (Anthropophonetics: remarks concerning the ecology of speech organs and the maintenance of the aesthetics of sounds in the public space). In Łobacz, P., P. Nowak and W. Zabrocki. (eds.). Language. Science and culture: essays in honor of Professor Jerzy Bańczerowski on the occasion of his 70th birthday. Poznań: Wadawnictwo Naukowe UAM. 301-315.

Puppel, S. 2014. „Komunikator ustny jako performer właściwie ułożony i właściwie licencjonowany w przestrzeni publicznej”. Studia Rossica Posnaniensia XXXIX. 315-321.

Puppel, S. 2019. "Uwagi w sprawie strategii zachowania lingworóżnorodności w kontekście bioróżnorodności". Humanistica 21.3. 59-71.

Puppel, S. (To be published). "W sprawie konieczności zachowania przedludzkich systemów komunikacyjnych (bezjęzykowych) w kontekście zachowania bioróżnorodności”. Studia Rossica Posnaniensia.

Rasmussen, J. 1986. Information processing and human-machine interaction: an approach to cognitive engineering. Amsterdam/New York: Elsevier.

Rossing, T.D. 2007. Springer handbook of acoustics. New York: Springer-Verlag.

Schafer, R.M. 1977. Tuning of the world. New York: Alfred Knopf.

Schafer, R.M. 1944. The soundscape: the tuning of the world. Rochester, NY: Inner Traditions International.

Vér, I.L. and L.L. Beranek. (eds.). 2006. Noise and vibration control engineering: principles and applications. New York: John Wiley and Sons.

Wilson, J.R. and N. Corlett. (eds.). 2005. Evaluation of human work. London: Taylor and Francis.

Woods, A. 1944/1987. The physics of music. London: Chapman and Hall. 